ARTIGO

Recebido em: 23/06/2016

Aceito em: 10/04/2017

\title{
0 uso do design thinking como ferramenta no processo de inovação em bibliotecas
}

Use of design thinking as a tool in the process of innovation in libraries

\author{
Diana Marcela Bernal RAMÍREZ (dimabera@yahoo.es)* \\ Thais Batista ZANINELLI (thais.zaninelli.uel@gmail.com)** \\ * Mestranda no Programa de Pós Graduação em Ciência da Informação da UEL. \\ ** Professora Do Departamento de Ciência da Informação da UEL.
}

\section{Resumo}

Este artigo tem como finalidade apresentar estudos de casos de sucesso do uso da abordagem do Design Thinking (DT) em bibliotecas e teve como objetivo estudar o Design Thinking através da história, as fases que compõem esta abordagem de inovação, bem como a importância da fase da prototipagem, e a relevância do Design Thinking na Ciência da Informação. Para tanto, foi realizada uma pesquisa bibliográfica, na qual foram pesquisadas bases de dados para a coleta de informações pertinentes, como artigos de periódicos da Capes, livros e páginas de internet. Como resultado da análise das informações se conseguiu identificar a importância do DT na área da Ciência da Informação e as vantagens que pode representar esta nova abordagem no contexto acadêmico e de negócios.

Palavras-chave: Design Thinking; Bibliotecas; Origem do Design Thinking; Fases do Design Thinking; Ciência da Informação

\begin{abstract}
This study to present a theoretical article on success stories of Design Thinking (DT) in libraries, which aimed to study the Design Thinking through of the story, the phases that make up this methodology, as well as the importance of the stage of prototyping, and the relevance of Design Thinking in Information Science. To this end, it was made a bibliographical research where databases employed to collect relevant information were the Capes journal articles, authors of books and internet pages. As a result of analysis of the information it was able to identify the importance of DT in the field of Information Science and the advantages that can represent this new methodology to a level academic and business.

Keywords: Design Thinking; Libraries; Origin of Design Thinking; Phases of Design Thinking; Information Science
\end{abstract}

v. 22, n. $49,2017$. p. $59-74$

ISSN 1518-2924

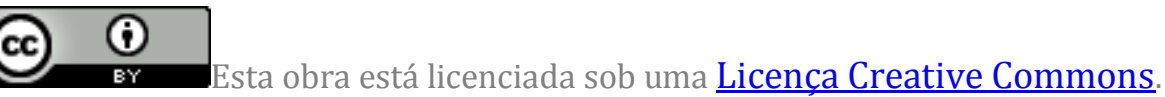




\section{INTRODUÇÃo}

Abordar o tema inovação, em especial o processo desenvolvimento de produtos e serviços de informação, exige uma reflexão acerca de quais são as características que definem inovação (BEHARRY; PUN, 2011; SCOZZI, GARAVELLI; CROWSTON, 2005) e como as bibliotecas universitárias utlizam as ferramentas voltadas para a inovação.

É notório que os serviços informacionais tradicionais oferecidos por estas organizações estão passando por significativas mudanças devido a vários fatores, que vão desde a mudança no comportamento dos usuários em relação ao ambiente físico da biblioteca até o rápido avanço na tecnologias de informação. Atualmente estes e outros fatores que serão abordados ao longo do texto causam impacto direto no sucesso do processo de inovação.

Dada esta crescente atenção, nas últimas décadas, um número notável de pesquisadores tem tentado identificar abordagens que são cruciais para o sucesso do processo de inovação em diferentes contextos (OSTROM, BITNER et al. 2010). Entretanto, devido à complexidade envolvente neste processo, este pode ser realizado por meio de diferentes abordagens, como, por exemplo, a abordagem proposta pelo Design Thinking (DT).

Basicamente, o DT é uma ferramenta de inovação, uma abordagem predominantemente de gestão, que se vale de técnicas que os designers usam para resolver problemas antigos de uma forma inovadora (NITZCHE, 2012; FASCINE, 2014). Assim, entender quais as abordagens que o DT propõe no âmbito das bibliotecas universitárias é um tema desafiador, uma vez que ambos os temas, inovação em serviços de informação e DT, ainda são pouco explorados em um mesmo contexto.

Nesse sentido, para estudar a abordagem do DT como suporte no processo de inovação nos serviços informacionais em bibliotecas universitárias, é necessário analisar como o comportamento das pessoas de forma geral está mudando. Isso porque, com a abertura dos mercados, a chamada globalização, em que todos os países e suas atividades foram melhor expostos ao mundo e essas mesmas atividades podem ser intercambiadas entre os países, havendo ajuda mútua, há evolução das nações.

Nesse contexto, McGrew e Lewis (1992) salientam que a globalização é [...] o processo pelo qual os eventos, as decisões e as atividades numa parte do mundo provocam repercussões significativas (e cada vez mais rápidas) para pessoas e comunidades de outro quadrante distante do mundo. Também implica uma intensificação do grau de interação, inter-relação e interdependência entre os estados e as sociedades que constituem a comunidade mundial.

Vale lembrar que os avanços tecnológicos vividos nos últimos anos, por um lado, trouxeram a evolução para as organizações e as pessoas, tanto no âmbito dos processos orgnizacionais quanto nas alterações no formato de comunicação; por outro lado, também trouxeram fechamentos de organizações que não conseguiram evoluir e se adpatar a esse novo cenário, pelo que se fez necessário olhar para outras alternativas (CASTELLS, 1998, p. 4).

Assim, nessa busca por alternativas para a sobrevivência das organizações neste atual cenário, para que as organizações, além de permanecerem no mercado, sejam competitivas, ganhou força o tema da inovação, ou seja, as empresas agora têm que pensar no todo, tais como nos colaboradores, nos clientes, nos usuários, nas novas características do mercado, enfim, os avanços das tecnologias de informação e comunicação diminuíram a distância, bem como os serviços que as empresas forneciam, pois desta forma foram eliminadas as fronteiras comerciais, sociais e culturais. E no âmbito dos serviços de informação das bibliotecas universitárias não foi diferente.

Em paralelo a estas mudanças, a empresa IDEO, organização reconhecida no mundo pelos projetos de sucesso, lançava-se no mercado da inovação (NITZSCHE, 
2012). Na contramão do fechamento de várias empresas, a IDEO se criava e se consolidava por meio da abordagem do DT. Segundo Nitzsche (2012, p. 42), um "programa de televisão de audiência nacional apresentou a IDEO ao público americano".

Assim, diante da importância da inovação no atual contexto econômico, o objetivo deste estudo foi analisar de que forma a abordagem do DT pode ajudar as bibliotecas universitárias a inovarem seus produtos e serviços de informação. No âmbito das bibliotecas universitárias esse tema é ainda mais desafiador, devido à mudança na forma que os universitários, classificados na literatura como os nativos digitais (RODI, et al., 2014), consomem a informação.

É importante ressaltar que esta pesquisa aborda os serviços informacionais no que tange a infraestrutura (evidências físicas que agregam valor ao ambiente físico) e os serviços tradicionais das bibliotecas universitárias (como, por exemplo, atendimento ao usuário, empréstimo, renovação, dentre outros). Portanto o foco deste estudo foi analisar de que forma a abordagem do DT pode contribuir no processo de inovação, por um lado na inovação do ambiente físico disponibilizado aos usuários e, por outro, na forma de como inovar no processo de prestação dos serviços tradicionais, já realizados diretamente aos usuários.

A contribuição do DT para a inovação dos serviços das bibliotecas universitárias tem se tornado uma ferramenta poderosa no que tange a melhoria do processo de inovação e de enfoque estratégico nestas instituições, devolvendo para as mesmas um ambiente diferente e chamativo para o público-alvo e também para a comunidade que está interessada em conhecer e consumir serviços informacinais inovadores.

Portanto, sendo o principal objetivo do estudo entender de que forma o DT potencializa o processo de inovação em bibliotecas universitárias, os resultados aqui apresentados podem ajudar os bibliotecários, diretores e gestores de Unidades de Informação a entender melhor como se dá o processo de inovação, bem como compreender o que os atuais usuários desejam em um ambiente informacional inovador.

\section{METODOLOGIA}

Para o desenvolvimento deste artigo teórico, foi realizada uma pesquisa bibliográfica, com uma abordagem qualitativa, que possibilitou o estudo sobre o processo de inovação por meio da abordagem do DT em bibliotecas universitárias.

A pesquisa bibliográfica se entende como a consulta em materiais já elaborados, que se constituem principalmente de livros e artigos científicos. Sua vantagem reside no fato de permitir ao investigador a cobertura de uma gama de fenômenos mais ampla (GIL, 2008; VERGARA 2005).

Para estudar a abordagem do DT no contexto das bibliotecas universitárias, foi realizada uma pesquisa bibliográfica, na qual foram estudados os artigos de periódicos da Capes, livros de autores renomados sobre DT, páginas de internet e algumas mídias sociais como Facebook e Twitter, para tanto, as palavras-chave adotadas foram "design", "design thinking", "design thinking em bibliotecas", "design thinking and libraries". A pesquisa foi feita nos meses de outubro, novembro e dezembro de 2015.

Deste modo, em uma primeira fase, foi realizada uma revisão extensa da literatura para caracterizar, conceituar e entender as fases envolventes no processo de inovação por meio da abordagem do DT.

$\mathrm{Na}$ segunda fase da pesquisa, buscaram-se, na literatura, casos reais de projetos de inovação em serviços em bibliotecas de forma geral e procurou-se entender como o design thinking também pode ser aplicado no processo de inovação em bibliotecas universitárias. 
Os resultados estão estruturados da seguinte forma: Inovação em serviços de informação; 0 que é e qual a origem do design thinking? Fases do processo de inovação pela obordagem do DT; 0 papel da prototipagem para o sucesso da inovação; A importância do DT para a ciência da informação. No final, apresentamos as considerações finais e sugestões para estudos futuros.

\section{INOVAÇÃO EM SERVIÇOS DE INFORMAÇÃO}

Inovação é tudo o que se refere à concepção e implantação de mudanças relevantes em um produto, em um serviço, em um processo, nas ações de marketing, com o objetivo de melhorar os resultados e a competitividade das empresas (MANUAL DE OSLO, 2005). "A inovação implica o uso de um novo conhecimento ou de uma nova combinação de conhecimentos existentes" (OCDE, 2005, p. 44).

Segundo Manuel de Oslo (2005), há quatro (4) tipos de inovações: (1) inovação de produto, (2) inovação de processo, (3) inovação em Marketing, (4) inovação na organização.

A inovação de produto se refere a um bem ou a serviço novo, ou melhorado significativamente, ou seja, algo físico ou técnico (materiais, componentes, etc.). Para que seja considerado inovação, é necessário que esse bem ou serviço seja diferenciado dos já existentes no mercado.

Já a Inovação no processo são as mudanças significativas em técnicas, materiais e/ou programas informáticos, assim como a qualidade dos mesmos, com o intuito de diminuir custos unitários de produção ou distribuição.

Com relação à inovação em marketing, a inovação acontece por meio do uso de um novo método de comercialização, conseguindo mudanças relevantes no desenho, posição (canais de venda), promoção (melhor comunicação) ou preço, com o propósito de incrementar as vendas.

Finalmente, a inovação na organização faz referência às mudanças nas práticas e procedimentos da empresa, assim como no local de trabalho e nas relações externas (clientes e fornecedores).

Em um passado recente, o principal foco das pesquisas em torno da inovação era principalmente no contexto das inovações relacionadas a artefatos tecnológicos, em outras palavras, em produtos físicos (HOWELLS, 2006; DROEGE, HILDEBRAND et al, 2009). Poucas pesquisas científicas aconteciam em torno do processo de inovação inerente aos serviços (SPOHRER, MAGLIO, 2010).

Inovação em serviços é a introdução de uma característica ou um conjunto de características (tecnológicas ou não tecnológicas) que propiciem a prestação de um serviço para o usuário final de uma nova maneira, ou de uma maneira melhorada. 0 usuário final deve reconhecer que o conjunto dessas características seja traduzido como benefício e tenha impacto em sua avaliação da prestação do serviço. (VASCONCELOS, MARX, 2011).

O primeiro autor a definir o processo de inovação em serviços foi Lovelook em 1984. Para Lovelook, a inovação em serviços pode acontecer em cinco categorias, a saber: (1) Novos negócios; (2) Novos serviços para a organização; (3) Extensão de categorias de serviços já existentes; (4) Melhorias de serviços; (5) Mudanças no estilo de prestação do serviço.

Relativamente à inovação em serviços de informação, Cruz-Riascos (2013) afirma que estamos na era da informação, do conhecimento e da inovação. Nesse contexto, se faz fundamental olhar para a inovação dos serviços informacionais e, neste estudo, o foco está nas bibliotecas universitárias, que devem, além de se aprimorarem na prestação de produtos e serviços presenciais, focar nos virtuais para atender os usuários digitais.

Cruz-Riascos (2013) ainda expõe que se faz importante agir de acordo com esta nova era digital, que estabelece uma maior interação social, gera e compartilha conhecimento, assim como uma inteligência coletiva. Isso porque, com essa nova era 
digital, faz-se indispensável - e é muito bom para as bibliotecas - o uso das mídias e entretenimento dos seus serviços para chamar a atenção dos usuários e fazer destes espaços lugares mais atraentes, além de aportar conhecimento e cultura para a sociedade.

Desta forma, podemos ressaltar que a inovação é um processo no qual é importante levar em consideração não só as ideias e o conhecimento dos designers ou engenheiros que desenvolvem os produtos e serviços, é relevante considerar as opiniões dos usuários, pois são eles que usarão esses produtos e serviços e ajudarão os profissionais a fazer melhor seu trabalho, de forma que o resultado seja bem sucedido e beneficie as duas partes: organização e usuário.

0 processo de inovação em serviço pode acontecer com base em várias abordagens apresentadas na literatura e envolve várias fases sequenciais, como, por exemplo, a proposta por Karlsson e Ahlstrom, (1997), que defendem que o processo de inovação deve seguir as seguintes fases: criação da ideia, execução, detalhamento do design, revisão e teste. Todas essas fases são desenvolvidas e executadas pelos fornecedores, gestores e pessoal de marketing e comercialização.

Esses e outros processos formais de inovação em serviços, que tiveram como base o processo de inovação em produtos, atualmente, são questionados por diversas empresas no âmbito do seu real valor e sobre o tempo e o impacto que esse processo realmente traz ao cliente, quando o mesmo é lançado no mercado.

Dessa forma, o processo de inovação em serviços com base na abordagem do DT tem sido cada vez mais estudado e adotado por organizações que realmente têm pressa no processo de inovação e desejam entender o que realmente o cliente deseja do novo serviço que será lançado.

Bill Burnett, especialista no estudo sobre inovação com base na abordagem do DT, ressalta dizendo que "o melhor design" é o que está por detrás dos serviços simples, fáceis de utilizar, que fazem com que os utilizadores se sintam inteligentes e poderosos. Bill Burnett ainda ressalta que o que faz a "diferença em um serviço é satisfazer as necessidades emocionais do utilizador", e isso a abordagem de inovação proposta pelo DT faz muito bem.

\section{DESIGN THINKING}

\subsection{0 que é?}

Design Thinking (DT) é uma disciplina que usa a sensibilidade do designer e os métodos de inovação para que coincidam as necessidades das pessoas com o que é tecnicamente possível e financeiramente viável para a organização e, assim, criar valor ao cliente (Brown, 2008).

O mesmo autor descreve que o DT "é inovação centrada na pessoa" (BROWN, 2010), na qual o designer busca compreender as preocupações das pessoas que está estudando para assim melhorar seu produto ou serviço, é criar empatia com o intuito de fazer desse produto ou serviço uma ajuda real para o usuário.

Para Dune e Martin (2006, p. 517),

0 design thinking é o caminho no qual os designers pensam: os processos mentais que eles usam para desenhar os objetos, serviços ou sistemas, a diferença é o resultado final de produtos diferenciados e úteis. (Tradução do autor)

O DT "é uma poderosa ferramenta de inovação que serve para melhorar ou transformar qualquer produto, serviço ou processo, [...] combina habilidades analíticas e criativas, de forma resumida e clara" (PONTI, 2015, p. 176). Esta abordagem da inovação foca no desenvolvimento de soluções limpas no que diz respeito à estética, assim como em novas funcionalidades, dessa forma origina novos conhecimentos e valor para o usuário (BONINI, ENDO, 2015). 
Entretanto, para que a inovação ocorra de fato, é importante a postura das pessoas envolvidas no processo de inovação. Segundo Tim Brown (2008), essas pessoas teriam que ter um perfil de Design Thinker, que envolve: Empatia, que pode ser definida como a capacidade de ver ou imaginar o mundo por diferentes pontos de vista (colegas, clientes, usuários) e sempre deve priorizar a pessoa, em outras palavras, é a pessoa que tem a capacidade de se pôr no lugar do outro; Pensamento integrador, o designer tem que ter a habilidade de não só focar nos processos analíticos, com também deve ser capaz de questionar e ver tudo aquilo que é importante para conseguir a melhoria.

Além dessas caraterísticas, o designer também deve ser otimista, sempre enxergar todas as possibilidades da melhor maneira; experimentador, deve questionar e ter soluções em "trilhos criativos" que orientem para novos caminhos; colaborador, o design thinker deve ser capaz de se relacionar com outras pessoas de outras especialidades.

Dessa forma, para levar a cabo um projeto que implique DT, deve-se ter uma forte equipe multidisciplinar, que segundo Steinbeck (2011, p. 28) é:

- Adquirir conhecimentos básicos sobre os usuários e sobre a situação ou problema geral. (Compreender)

- Conseguir empatia com os usuários enxergando-os de perto. (Observar).

- Criar um usuário típico para o qual se está desenhando uma solução ou um produto. (Definir o ponto de vista).

É claro que os "design thinkers" - profissionais que trabalham o processo de inovação com base na abordagem do DT - devem compreender muito bem a necessidade do usuário para quem farão a inovação do produto, serviço ou processo, mas além disso, contar com aquelas caraterísticas citadas por Brown, com o intuito de conseguir um trabalho bem sucedido.

\subsection{Origem}

A tabela a seguir apresenta alguns dos autores que deram início ao tema e às discussões sobre o DT. 
Quadro 1: Origens do design thinking1.

\begin{tabular}{|c|l|}
\hline Autor & \multicolumn{1}{c|}{ Conceito de Design } \\
\hline $\begin{array}{c}\text { Herbert Alexandre Simon } \\
\text { (1969) }\end{array}$ & $\begin{array}{l}\text { Design com o conhecimento nos processos da engenharia, gestão ou } \\
\text { medicina, aqueles preocupados com "o que deveria ser". } \\
\text { No seu livro Administrative Behavior (1947), expõe a importância do } \\
\text { design na tomada de decisões, a qual compreende três (3) elementos: } \\
\text { inteligência, design e escolha. } \\
\text { Daí uma frase dele sobre design thinking: "Quem projeta cursos de ação } \\
\text { para transformar situações existentes em outras preferidas, faz design." }\end{array}$ \\
\hline \multirow{2}{*}{ Peter Gorb (1970) } & $\begin{array}{l}\text { Contribuiu com o design management, argumentando que para que os } \\
\text { designers fossem integrais, deviam aprender a linguagem dos negócios } \\
\text { (linguagem contável e financeira). } \\
\text { Essa gestão do design é vista como a base para o design thinking, a } \\
\text { tecnologia, a gestão corporativa e a gestão de marca. }\end{array}$ \\
\hline Peter G. Rowe (1987) & $\begin{array}{l}\text { Pensamento visual composto por três atividades: desenho da ideia (idea- } \\
\text { sketching), visualização (seeing), e imaginação (imagining). }\end{array}$ \\
\hline IDEO (1991) & $\begin{array}{l}\text { Publicou o livro Design Thinking sobre arquitetura e planejamento } \\
\text { urbano, visto ele como um processo de design. }\end{array}$ \\
\hline Rolf Faste (1980 - 1990) & $\begin{array}{l}\text { Expandiu os estudos feitos por Mckim na Universidade de Stanford no } \\
\text { curso de Engenharia Mecânica. } \\
\text { Faste trouxe grandes contribuições aos campos de design focado no } \\
\text { homem e no ensino do design. } \\
\text { Escreveu vários livros como, por exemplo, "Forget Design Thinking and } \\
\text { Try Hybrid Thinking" e foi o mentor de David Kelley, o fundador de IDEO. } \\
\text { Faste trabalhou muito para a definição de design thinking e tentou } \\
\text { expressar o único rol que os designers poderiam desenvolver para fazer } \\
\text { quase tudo. }\end{array}$ \\
\hline $\begin{array}{l}\text { Empresa fundada por David Kelley, é a empresa mais respeitada no } \\
\text { mundo da inovação por apresentar e testar a sua metodologia de Design } \\
\text { Thinking, a qual é centrada no usuário e é composta por cinco passos: } \\
\text { compreender, observar, visualizar, avaliar e implementar. }\end{array}$ \\
\hline
\end{tabular}

Fonte: Elaborado pelo autor.

Como visto no quadro, o conceito de DT foi se desenvolvendo através dos anos com diferentes nomes, mas sempre a base foi o design. 0 grande desenvolvimento foi focar o processo de inovação nas pessoas, que realmente são os usuários do produto ou do serviço.

Levando em consideração que o DT é uma abordagem de inovação, que conta com algumas etapas ou fases para sua realização e sucesso, a seguir serão explicadas em detalhes as principais fases que compõem essa abordagem: inspiração, ideação e implementação.

\subsection{Fases da abordagem do Design Thinking}

Como todo processo de inovação, a abordagem proposta pelo DT apresenta algumas fases, assim, uma vez se tenha identificado o problema, começam a surgir esses grandes e importantes acontecimentos ou etapas do DT, que segundo Brown (2008) se dão em três (3) fases, como seguem apresentadas na figura 1.

1 Tomado e adaptado de NITSZCHE, Rique. Afinal, o que é design thinking? E SIMON, Herbert A. The Sciences of the Artificial, e nosmut(dot)com disponível em: $<$ http://web109.srv4.sysproserver.de/Design_thinking.html>. 


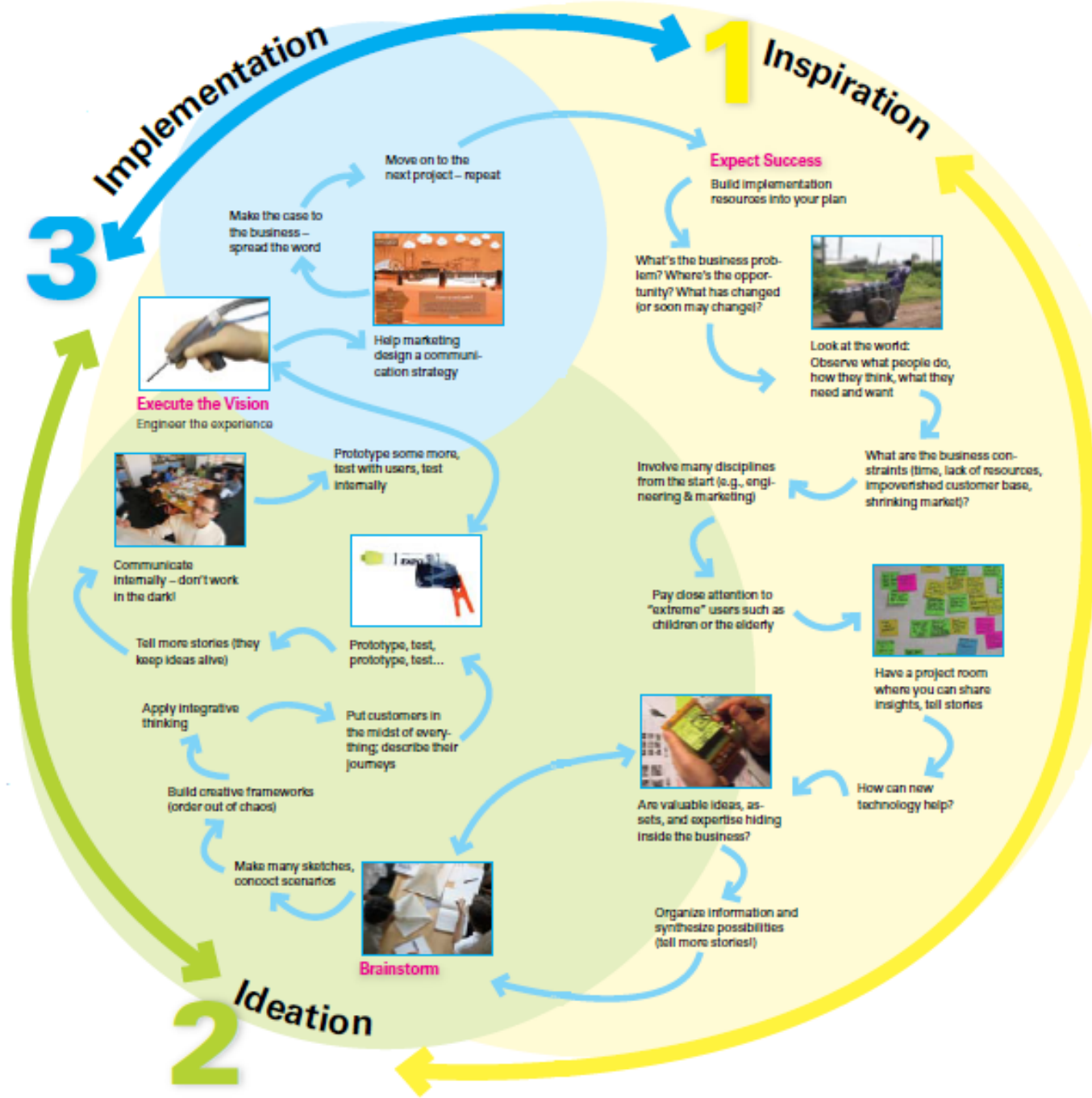

Figura 1: Como acontece a inovação com base na abordagem proposta pelo Design Thinking. Fonte: BROWN, 2008, p. 88 - 89.

De acordo com a imagem, no primeiro estágio, inspiração, o que é necessário levar em consideração é que se deve ter uma expectativa de sucesso, deve-se construir no plano os recursos de implementação e enxergar o problema a ser solucionado, é necessário ver ao redor e trabalhar com outras disciplinas para consegui-lo, assim como utilizar todas as ajudas (tecnológicas, observação, reuniões, etc.) que podem contribuir para o objetivo final.

Após o estágio da inspiração, chega a ideação, na qual o importante é levar a cabo o brainstorming, com a finalidade de criar cenários e rascunhos para originar um marco de referência e a partir dele empregar esse pensamento integrador que deve ter o design thinker, para que, num segundo momento, possa levar esses rascunhos ao consumidor para que ele relate a sua experiência e, desta forma, criar o protótipo e depois testá-lo com o usuário várias vezes, até que ele goste. São nesses espaços que os designers se comunicam com seu grupo de trabalho, para melhorar a experiência do cliente.

Finalmente, feito o protótipo ou produto, serviço ou processo e testado não só pelo consumidor, mas também pela equipe de maneira interna, vem a implementação. Esse passo é bem importante e de muito cuidado, pois é aqui que se dará realidade ao rascunho; é nesta etapa que se executa a visão e que os profissionais especializados entram em cena, relacionam-se com as áreas de 
marketing e comunicação estratégica, para que haja uma efetiva divulgação da inovação ao consumidor.

Para Steinbeck (2011, p. 29), o mais importante é que a equipe que trabalha no novo projeto seja interdisciplinar, pois isso garante:

- $\quad$ Gerar todas as ideias possíveis. (Idear).

- Construir protótipos reais baseados em ideias promissoras. (Construir protótipos).

- Aprender com base nas reações dos usuários frente aos diferentes protótipos. (Provar).

Para complementar a explicação, o Hasso-Plattner-Institut (HPI), School of Design Thinking, expõe que a inovação por meio da abordagem do DT é um processo iterativo composto por diferentes fases.

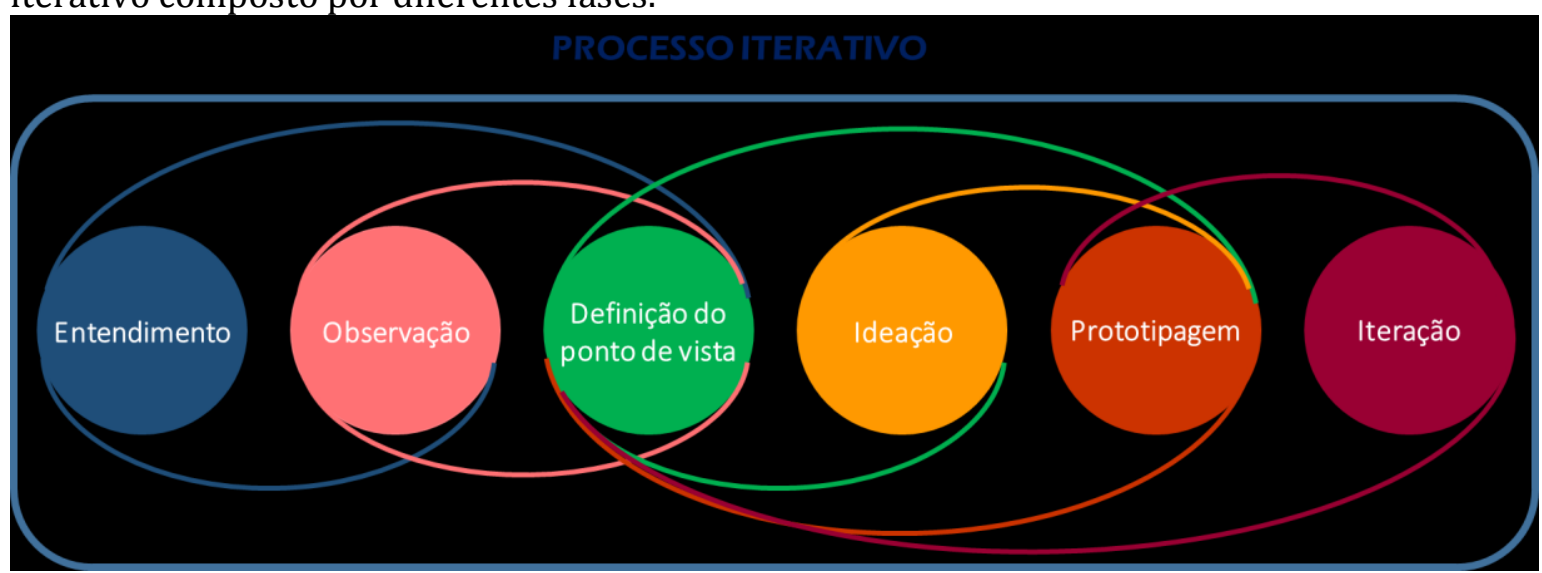

Figura 2: Processo de Design Thinking

Fonte: School of design thinking (2015)

Com base nos dois modelos, pode-se observar que há três etapas que são comuns: definição do ponto de vista ou inspiração, a ideação e a prototipagem, que com as diferentes iterações e testes servirá de base para a implementação do produto, do serviço ou do processo.

\subsubsection{O papel da prototipagem para o sucesso da inovação}

Segundo Ponti (2015), a característica principal do DT é a prototipagem das ideias, pois com esta se pode constatar se realmente o que foi pensado funciona. 0 referido autor emprega a expressão "pensar com as mãos", a qual expressa que à medida que vai aperfeiçoando o protótipo, consegue-se resolver o problema inicial.

Assim, o protótipo é muito relevante no DT, pois significa transformar a ideia inicial em "realidade", em algo tangível, que a equipe multidisciplinar pode testar, melhorar e repensar a inovação, com o propósito de satisfazer a necessidade do usuário.

Além disso, com o resultado da prototipagem, o ganho mais importante é o aprendizado sobre as fortalezas e as oportunidades de melhoria da ideia, que por sua vez identifica novos caminhos para esse protótipo. Vale ressaltar que a importância do protótipo é muito grande, porque à medida que ele exemplifica a ideia para o usuário, vão se fechando ou eliminando erros e vai se assegurando o sucesso da inovação.

Brown (2010, p. 83) considera a prototipagem como "[...] um dos processos mais fundamentais por meio dos quais exploramos o universo, liberamos nossa imaginação e abrimos a mente para novas possibilidades". Portanto a prototipagem é a melhor maneira de experimentar, pois por meio dela é possível observar os resultados mais rapidamente, por isso o autor recomenda que quanto mais cedo se faça o tangível, a ideia (sendo esta rudimentar e barata) do produto, serviço ou 
processo, mais veloz será a sua avaliação, lapidação e a identificação da melhor solução.

O autor também expõe que "os protótipos só devem consumir o tempo, o empenho e o investimento necessários para gerar feedbacks úteis e levar uma ideia adiante" (BROWN, 2010, p. 86). Pois o que inicialmente se pretende com a prototipagem é identificar uma forma mais fácil de o consumidor visualizar a ideia, é mais que um modelo funcional, pois assim podem ser identificados os pontos fortes e fracos para conseguir novas orientações para os outros protótipos e finalmente ter a satisfação do usuário para continuar com a implementação do produto, serviço ou processo.

Finalmente, a prototipagem deve englobar três aspectos importantes para que seja bem sucedida, segundo Brown (2010): inspiracional, para gerar outros protótipos que desenvolvam uma ideia e que em cada um deles a equipe aprenda e continue em frente; também deve ter um espaço de idealização, onde se assegure a incorporação de informações funcionais e emocionais suficientes para compreender a demanda do mercado; e finalmente a implementação, a qual deve garantir a clareza da ideia para ser aceita pela empresa e que se evidencie que funcionará no mercado escolhido.

Pode-se concluir que a importância da prototipagem se dá na medida em que ajuda a esclarecer a ideia para a inovação o mais cedo possível, etapa em que os custos de investimento serão mínimos. Conforme o protótipo vai sendo testado, há o envolvimento tanto de assuntos funcionais como emocionais, cumprindo com o objetivo de se focar nas pessoas, esse viés é muito importante, pois essas iterações, além de melhorar ou aperfeiçoar o protótipo, paralelamente a equipe aprende, gerando assim novos conhecimentos e soluções aos problemas existentes.

\section{DESIGN THINKING NO CONTEXTO DA CIÊNCIA DA INFORMAÇÃO}

Com base no exposto, pode-se inferir que o DT é uma ferramenta poderosa para gerar inovação em qualquer contexto que seja aplicado, assim como consegue que essa inovação seja voltada para o usuário, dando-lhe a importância necessária, levando em consideração suas crenças e ideias de melhoria para os produtos, serviços ou processos que serão aperfeiçoados para eles.

Uma vez que o DT foca no usuário, Brown (2010, p. 37) ressalta que "precisamos aprender a colocar as pessoas em primeiro lugar". Portanto, pode-se considerar que no caso da Ciência da Informação (CI) este processo ganha importância, já que no âmbito dessa área do conhecimento se desenvolve o estudo de usuário nas bibliotecas, o qual é feito pelos profissionais desta área. Para Figueiredo (1994), os estudos de usuários são pesquisas desenvolvidas para saber as necessidades de informação dos usuários ou para ponderar a consideração das necessidades de informação pelas bibliotecas e pelos centros de informação.

Pode-se compreender que a importância do DT para a Ciência da Informação se dá no sentido que os dois têm como foco o usuário. No caso dos estudos de usuários desenvolvidos nesta área do conhecimento, o DT pode ser visto como um excelente complemento para poder não só identificar as necessidades dos usuários, mas criar um melhor serviço para eles. Ajuda também os gestores e bibliotecários a desenvolverem serviços informacionais inovadores, atraindo mais usuários à biblioteca.

\subsection{Design Thinking e as Bibliotecas: Casos de Sucesso}

A abordagem do DT tem sido utilizada no contexto das inovações em serviços de informação, em especial nas bibliotecas, e a literatura tem evidenciado casos de sucesso, não só nos Estados Unidos, através da Biblioteca Pública de Chicago, como também no Brasil com a Biblioteca da Universidade do Estado de Santa Catariana e na Colômbia com o Sistemas de Bibliotecas de Bogotá. 


\subsubsection{Biblioteca Pública de Chicago}

Esta biblioteca é uma das mais renomadas nos casos de sucesso de aplicação da abordagem do DT, que pretendeu responder à questão: Como se poderia integrar um parque infantil no ambiente dos serviços das crianças na biblioteca de Chicago?

Com este questionamento, a equipe aceitou o desafio, conseguiu informações e atividades interessantes para as crianças, famílias, sociedade e para a própria biblioteca. A seguir se apresenta um quadro com os itens importantes desenvolvidos neste projeto.

Quadro 2: Processo de Design Thinking na Biblioteca de Chicago

\begin{tabular}{|c|c|c|}
\hline Fases do DT & Como foi realizado & Resultados obtidos \\
\hline Inspiração & $\begin{array}{l}\text { A equipe realizou: } \\
\text { - Entrevistas e observação das crianças nos } \\
\text { museus direcionados para eles. } \\
\text { - Entrevistas com crianças "experts" em assuntos } \\
\text { de jogos (brincadeiras). } \\
\text { - Entrevistas com as famílias. }\end{array}$ & \multirow{4}{*}{$\begin{array}{l}\text { Com a aplicação do protótipo } \\
\text { ao público alvo, a equipe } \\
\text { aprendeu o seguinte: } \\
\text { - As famílias precisavam } \\
\text { estruturar as atividades, } \\
\text { pelo menos até que a } \\
\text { brincadeira se tornasse } \\
\text { rotina. } \\
\text { - As famílias precisam estar } \\
\text { presentes, pois não estão } \\
\text { acostumadas a isso na } \\
\text { configuração da biblioteca. } \\
\text { - Alguns membros do } \\
\text { pessoal da biblioteca } \\
\text { precisam mudar a } \\
\text { perspectiva do barulho e o } \\
\text { controle, o qual requer } \\
\text { capacitação e mudança nas } \\
\text { crenças pessoais. }\end{array}$} \\
\hline Ideação & $\begin{array}{l}\text { Com os resultados obtidos nas entrevistas e a } \\
\text { observação, a equipe destacou quatro (4) pontos: } \\
\text { - As bibliotecas são percebidas como o terceiro } \\
\text { lugar mais seguro depois da escola e o lar. } \\
\text { - As bibliotecas poderiam ser parte do processo } \\
\text { de criação de vida das crianças. } \\
\text { - Pais e bibliotecários tendem a ter controle para } \\
\text { estruturar as brincadeiras. } \\
\text { - Os pais com filhos em idade escolar desejam } \\
\text { que se separe o estudo das brincadeiras. }\end{array}$ & \\
\hline Prototipagem & $\begin{array}{l}\text { A equipe desenhou com espumas bonecos para } \\
\text { conseguir um novo espaço para que as crianças } \\
\text { contem histórias, com fantoches feitos à mão. }\end{array}$ & \\
\hline Iteração & $\begin{array}{l}\text { Foram convidadas crianças para inventarem uma } \\
\text { história em quadrinhos, fosse com personagens } \\
\text { conhecidas ou não. As crianças gostavam de } \\
\text { desenhar histórias de quadrinhos nas janelas e } \\
\text { criar seu próprio livro de histórias. }\end{array}$ & \\
\hline
\end{tabular}

Fonte: Adaptado do Design Thinking for Libraries (2015)

\subsubsection{Biblioteca Universidade do Estado de Santa Catariana (UDESC)}

Nesta biblioteca, o que se pretendia fazer era a criação de um espaço acessível para atender pessoas com deficiência na Biblioteca Universitária (BU/UDESC). Nessa instituição realizaram as seguintes atividades, como seguem apresentada no quadro 3. 
Quadro 3: Aplicação do Design Thinking na BU/UDESC

\begin{tabular}{|c|c|c|}
\hline Fases do DT & Como foi realizado & \multirow{5}{*}{$\begin{array}{l}\text { Resultados obtidos } \\
\text { - } \text { Comunidade demandou } \\
\text { atividades culturais. } \\
\text { - Localização inadequada do } \\
\text { prédio. } \\
\text { - Número insuficiente de } \\
\text { tomadas elétricas. } \\
\text { - Pouco acesso à reserva de } \\
\text { salas. } \\
\text { - } \text { Barulho. } \\
\text { - Informação menos formal. } \\
\text { - Informação sobre cursos da } \\
\text { - UDESC. } \\
\text { - } \text { Informação sobre concursos } \\
\text { - } \text { Acesso a e-books. } \\
\text { Malote (pontos estratégicos dentro } \\
\text { da UDESC). } \\
\text { - Projeção de filmes com } \\
\text { debates. Seção infanto-juvenil. } \\
\text { - Ambientes de lazer } \\
\text { descanso. Salas de estudo individuais } \\
\text { - Auditório para cursos } \\
\text { palestras e reuniões. } \\
\text { - Sala com computadores com } \\
\text { acesso à internet para uso } \\
\text { da comunidade. }\end{array}$} \\
\hline Imersão & $\begin{array}{l}\text { Levantamento de dados por meio de entrevistas } \\
\text { e grupo focal. Entrevistou a comunidade externa } \\
\text { local, docentes, discentes e bibliotecários. }\end{array}$ & \\
\hline $\begin{array}{l}\text { Análise e } \\
\text { Síntese }\end{array}$ & $\begin{array}{l}\text { Síntese de: } \\
\text { - Entrevistas. } \\
\text { - Grupo focal referente às dificuldades. } \\
\text { - Grupo focal referente a } \\
\text { informação/produtos. } \\
\text { - Grupo focal referente a serviços/espaços. }\end{array}$ & \\
\hline Ideação & $\begin{array}{l}\text { Foram selecionadas quatro (4) ideias principais: } \\
\text { - Sinalização da BU. } \\
\text { - Serviço de informação turística. } \\
\text { - Grupos de interesse (acessibilidade, } \\
\text { interculturais, infantil, entre outros). } \\
\text { - Papa livros. }\end{array}$ & \\
\hline Prototipagem & $\begin{array}{l}\text { Foi recomendado deixar um espaço no térreo } \\
\text { com todo o equipamento de uma biblioteca } \\
\text { (produtos e serviços), além de programas } \\
\text { culturais. }\end{array}$ & \\
\hline
\end{tabular}

Fonte: Adaptado de JULIANI; CAVAGLIERI; MACHADO (2015)

\subsubsection{Sistemas de Bibliotecas de Bogotá - Colômbia (Biblored)}

As redes de bibliotecas em Bogotá têm como slogan cultura para a sustentabilidade. 0 projeto de bibliotecas surge devido à grande quantidade dessas instituições na cidade. Foi realizada uma classificação dessas instituições como Bibliotecas maiores, locais e de bairro, com o intuito de contribuir com o melhoramento da qualidade de vida, a inclusão, o enriquecimento do capital humano, social e cultural, assim como fortalecer a participação cidadã, dando prioridade às populações em desvantagem e/ou em condição de vulnerabilidade ${ }^{2}$. A seguir se apresenta o que foi desenvolvido nesta cidade para as bibliotecas.

${ }^{2}$ Tomado e adaptado de http://www.biblored.gov.co/Quienes-Somos/Acerca-de-BibloRed. 
Quadro 4: Resumo de caso de sucesso com bibliotecas em Bogotá - Colômbia

\begin{tabular}{|c|c|c|}
\hline Fases do DT & Como foi realizado & Resultados obtidos \\
\hline Imersão & $\begin{array}{l}\text { - Análise da situação dos serviços das } \\
\text { bibliotecas em Bogotá, assim como levar } \\
\text { em consideração o Plano de } \\
\text { Desenvolvimento Econômico, social e de } \\
\text { Obras Públicas na cidade. } \\
\text { - Contribuir com o melhoramento da } \\
\text { qualidade de vida, a inclusão, o } \\
\text { enriquecimento do capital humano, social } \\
\text { e cultural. } \\
\text { - Ampliar o acesso aos espaços públicos de } \\
\text { promoção à leitura da cidade, } \\
\text { distribuindo, de forma igualitária e } \\
\text { planejada, as bibliotecas e o acervo de } \\
\text { livros no território. } \\
\text { - Reduzir o índice de violência local a partir } \\
\text { do acesso à cultura. } \\
\text { - Facilitar o acesso aos espaços públicos de } \\
\text { cultura por meio da rede de transportes. }\end{array}$ & $\begin{array}{l}\text { - Os investimentos em cultura } \\
\text { começam a mudar a imagem de } \\
\text { um país associado à guerrilha, } \\
\text { narcotráfico e violência. } \\
\text { - Bogotá conta com } 20 \text { bibliotecas } \\
\text { espalhadas pela cidade de forma } \\
\text { estratégica e } 1 \text { "Bibliobús", que } \\
\text { fica instalado temporariamente } \\
\text { em pontos distintos da cidade, } \\
\text { contemplando territórios sem o } \\
\text { acesso ao serviço. } \\
\text { - Por meio de um serviço de } \\
\text { consultoria, a BiblioRed atende a } \\
\text { um total de } 59 \text { bibliotecas } \\
\text { comunitárias e realiza suporte } \\
\text { técnico a fim de: a) desenvolver } \\
\text { processos de planejamento e } \\
\text { implementação dos serviços de }\end{array}$ \\
\hline $\begin{array}{l}\text { Análise e } \\
\text { Síntese }\end{array}$ & $\begin{array}{l}\text { - Foram selecionados os seguintes aspectos: } \\
\text { - Quantidade de bibliotecas de Bogotá. } \\
\text { - Infraestrutura das bibliotecas para atrair a } \\
\text { comunidade. } \\
\text { - Identificar populações em desvantagem } \\
\text { e/ou em condição de vulnerabilidade. }\end{array}$ & $\begin{array}{l}\text { biblioteca; b) fortalecer as } \\
\text { coleções de bibliotecas; c) } \\
\text { orientar a gestão dos recursos } \\
\text { para seu desenvolvimento e } \\
\text { sustentabilidade dentro das } \\
\text { localidades. } \\
\text { - A Unesco escolheu Bogotá como } \\
\text { a primeira cidade latino- } \\
\text { americana a ser Capital Mundial } \\
\text { do Livro, em } 2007 \text {. } \\
\text { - Uma rede de ciclovias de } 300\end{array}$ \\
\hline $\begin{array}{c}\text { Ideação e } \\
\text { Implementaç } \\
\text { ão }\end{array}$ & $\begin{array}{l}\text { - Construção do sistema atual de transporte. } \\
\text { - Melhoria nos espaços dos pedestres. } \\
\text { - Criação de ciclovias. } \\
\text { - 2001: Bibliotecas são estruturadas e } \\
\text { classificadas em diferentes níveis, de } \\
\text { acordo com sua infraestrutura. }\end{array}$ & $\begin{array}{l}\text { corredores servem a todas as } \\
\text { grandes bibliotecas, as quais } \\
\text { interferiram diretamente no } \\
\text { planejamento do transporte } \\
\text { público da cidade. } \\
\text { - A Fundação Bill e Melinda Gates } \\
\text { doou US\$ } 1 \text { milhão para a rede } \\
\text { municipal de bibliotecas e } \\
\text { colabora com equipamentos } \\
\text { tecnológicos para os centros. }\end{array}$ \\
\hline
\end{tabular}

Fonte: Adaptado de PROGRAMA DE CIDADES SUSTENTÁVEIS, 2015.

Como apresentado nos três (3) casos, realmente houve contribuição à comunidade e, além disso, foi possível dar uma nova imagem a estas bibliotecas, foram concebidos mais atrativos para o público, além de melhorar a cultura da sociedade, também contribuindo com novos espaços para promover o lazer e jogos como parte central da aprendizagem dos usuários.

\section{CONSIDERAÇÕES FINAIS}

Devido à rápida mudança do mercado e da mesma forma as necessidades dos indivíduos, apresenta-se o DT como uma abordagem que apoia as empresas ou instituições que querem ficar à frente dessas mudanças, conseguindo ser in ovadoras em produtos, serviços ou processos, com o foco no usuário, uma vez que ele é parte importante do processo de inovação adotado em empresas. Assim, a utilização do DT pode gerar não só uma vantagem competitiva no mercado, mas também uma maior satisfação por parte dos usuários do produto ou serviço, criando, dessa forma, a fidelidade dos mesmos às organizações. 
A contribuição do DT para a inovação dos serviços das bibliotecas tem se tornado uma poderosa ferramenta de melhoria e de enfoque estratégico nestas instituições, devolvendo para as mesmas uma atmosfera / um ambiente diferente e chamativo para o público, não só que frequenta a biblioteca, mas para a comunidade que está se interessando por conhecer os novos serviços oferecidos. Dessa maneira, contribui-se com o crescimento da cultura e da educação na sociedade, fazendo com que haja motivação para a leitura e para investigar os diferentes assuntos que o usuário sinta interesse, gerando, assim, confiança por parte do usuário para com a biblioteca, pois ela já conhece as necessidades do seu público e sabe como atendêlas.

Nessa abordagem de inovação, ou seja, no DT, a fase de prototipagem é uma etapa muito importante, é quando se concretizam os desejos ou necessidades dos usuários; é o momento da observação da equipe de DT que assumiu o desafio de se colocar no lugar dos usuários e dessa forma vivenciar o que eles precisam.

Como visto nos casos de sucesso das bibliotecas, em que converteram um espaço "comum", sem muito interesse das pessoas, em um ambiente agradável para visitar com maior frequência. Com isso, o que se consegue é que se criem espaços não só de conhecimento e de compartilhamento de informação, e sim espaços de lazer, cultura e entretenimento para todas as idades, o que também contribui para o crescimento de uma sociedade equitativa e educada, o que gera novos conhecimentos.

\section{REFERÊNCIAS}

BEHARRY, A. K.; PUN, K. F. Managing Innovation Practices of SMEs in the Caribbean: An Exploratory Study. IEEE Int/l Technology Management Conference Managing Proceeding, 2011.

BIBLORED. Biblored Red Capital de Bibliotecas Públicas. Disponível em: <http://www.biblored.gov.co>. Acesso em: $01 \mathrm{dez} .2015$.

BOCCATO, V. R. C. Metodologia da pesquisa bibliográfica na área odontológica e o artigo científico como forma de comunicação. Revista de Odontologia da Universidade Cidade de São Paulo. São Paulo, v. 18, n. 3, p. 265-274, 2006.

BONINI, Luiz; ENDO, Gustavo. Bilbioteca Terra Forum Consultores. Disponível em: <http://www.terraforum.com.br>. Acesso em: 15 out. 2015.

BROWN, Tim. Design thinking. Harvard Business Review, v. 86, n. 6, p. 85-92, jun. 2008.

BROWN, Tim. Ideo. 2010. Disponível em: <https://www.ideo.com/about/>. Acesso em: 21 nov. 2015.

BROWN, Tim. Uma metodologia poderosa para decretar o fim das velhas ideias design thinking. Rio de Janeiro: Elsevier, 2010, 249 p.

CASTELLS, Manuel. Conferencia de UNRISD, publicado no periódico UNRISD

News. Informational Capitalism and Social Exclusión, n. 19, outono - inverno, p. 4-6. (1998).

CASTELLS, Manuel. Informational Capitalism and Social Exclusión, n. 19, outono - inverno, páginas 4-6, 1998

CRUZ-RIASCOS, Sonia. Inovação em serviços e produtos de informação para a sustentabilidade das bibliotecas das Instituições Federais de Ensino Superior brasileiras: de Gutenberg às redes virtuais. In: Congresso Brasileiro de Biblioteconomia, Documentação e Ciência da Informação, 25, 2013, Florianópolis, Anais... Florianópolis SC, Brasil, 2013, p. 1 - 13. 
DUNE, David; MARTIN, Roger. Design thinking and how It will change management education: an interview and discussion. Academy of Management Learning \& Education, v. 5, n. 4, p. 512-523. 2006.

DROEGE, H. D; HILDEBRAND, et al. Innovation in services: present findings, and future pathways. Journal of Service Management, v. 20, n. 2, p. 131-155. 2009.

FASCINE, Ligia. 0 que é o Design Thinking. 2014. Disponível em: <http://www.ideiademarketing.com.br/2012/02/06/o-que-e-design-thinkingentrevista-com-ligia-fascioni/>. Acesso em: 06 abr. 2014

FIGUEIREDO, Nice. Estudos de uso e usuários da informação. Brasília: IBICT, 1994. $154 \mathrm{p}$.

GIL, Antonio. Métodos e Técnicas de Pesquisa Social. 6 ed. São Paulo: Atlas, 2008.

HASEN, Morten; BIRKINSHAW, Julian. La cadena de valor de la innovación. Harvard Business Review, v. 85, n. 6, p. 106 - 116, jun. 2007.

HASSO - PLATTNER - INSTITUT. School of Design Thinking. Disponível em: <http://hpi.de/en/school-of-design-thinking/design-thinking/mindset.html>. Acesso em: 22 nov. 2015.

HOWELLS, J. Where to from here for services innovation? Paper presented at the Knowledge Intensive Services Activities (KISA) Conference, Sydney, 22 March 2006.

IDEO. Design thinking for libraries: A toolkit for patron-centered design.

Disponível em: <http://designthinkingforlibraries.com/>. Acesso em: 30 nov. 2015.

JULIANI, Jordan; CAVAGLIERI, Marcelo; MACHADO, Raquel. Design Thinking como ferramenta para a geração de inovação: um estudo de caso da Biblioteca Universitária da UDESC. InCID, Ribeirão Preto, v. 6, n. 2, p. 66 - 83, set. 2015.

KARLSSON, C.; AHLSTROM, P. Perspective: changing product development strategya managerical challenge. Journal of Product Innovation Management, v. 6, n. 14, p.473-484, 1997.

LOVELOOK, C.H. Developing and implementing new services. In: George, W.R and Marshal, C. E. (eds). Developing New Services, American Marketing Association, Chicago: IL, 1984. p. 44-64.

MCGREW, Anthony; LEWIS, Paul. Globalisation and the Nation States, Cambridge, Inglaterra, Polity Press, 1992. 352 p.

MCKIM, Robert. A. Experiences in visual thinking. Brooks/Cole Publishing Company, 1980.183 p.

NITZSCHE, Rique. Afinal o que é design thinking?. São Paulo: Rosari, 2012, 208 p.

NOSMUT(DOT)COM. Design thinking. Disponível em:

$<$ http://web109.srv4.sysproserver.de/Design_thinking.html>. Acesso em: 28 nov. 2015.

OCDE. Manual de Oslo: Guía para la recogida e interpretación de datos sobre innovación. 3. ed. España: Grupo Traga. 2005. 194 p.

OSTROM, A.; BITNER, M. et al. Moving forward and making a difference: research priorities for the science of service. Journal of Service Research, v. 13, n. 1 p. 4, 2010.

PONTI, Franc. Design thinking. Avianca em revista. Bogotá, v. 2, n. 30, p. 176, nov. 2015. 
PROGRAMA DE CIDADES SUSTENTÁVEIS. Bibliotecas em Bogotá. Disponível em: <http://www.cidadessustentaveis.org.br/boas-praticas/bibliotecas-em-bogota>. Acesso em: 01 dez. 2015.

RODI, A. F. et al. A case study: are digital natives dead? What are the key factors and perceptions librarian's view of the digital native culture in higher education?. Issues in Information Systems, v. 15, n. 2, p. 207-213, 2014.

ROWE, Peter G. Design Thinking. Cambridge, Massachuttes: The MIT Press. 1987. $229 \mathrm{p}$.

SCOZZI, B. : GARAVELLI, C.; CROWSTON, K. Methods for modeling and supporting innovation processes in SMEs. European Journal of Innovation Management, v. 8, n. 1, p. 120-137, 2005.

SIMON, Herbert A. The Sciences of the Artificial. MIT Press, Cambridge, Mass, 1969.

SPOHRER, J.; Maglio, P.P. Toward a science of service systems: Value and symbols. In: Maglio, P.P.; C. A. Kieliszewski and J. C. Spohrer (Eds.). Handbook of service science. New York: Springer. 2010.

STEINBECK, Reinhold. Design thinking como estrategia de creatividad en la distancia Revista Científica de Educomunicación, v. 19, n. 37, p. 27-35. iut. 2011.

VASCONCELLOS, Luís; MARX, Roberto. Como ocorrem as inovações em serviços? Um estudo exploratório de empresas no Brasil. Gestão \& Produção, v. 18, n. 3, p. 443460, 2011.

VERGARA, Sylvia. Projetos e relatórios de pesquisa em Administração. 6. ed. São Paulo: Atlas, 2005. 